\title{
中国瘤棘奈氏虫种群密度和形态特征的时空差异 及其影响因子
}

王文平 ${ }^{1,2}$, 高肖飞 ${ }^{1,3}$, 陈辉煌 ${ }^{1,2}$, 任可欣 ${ }^{1}$, 金䂞 $^{1,2}$, 杨军 $^{1^{*}}$

1. 中国科学院城市环境研究所, 中国科学院城市环境与健康重点实验室, 福建省流域生态重点实验室, 水生态健康研究组, 厦门 361021 ;

2. 中国科学院大学, 北京 100049 ;

3. 河南师范大学水产学院, 新乡 453007

*联系人, E-mail: jyang@iue.ac.cn

2021-06-20 收稿, 2021-09-09 修回, 2021-09-09 接受, 2021-09-10 网络版发表

国家自然科学基金(31672312，91851104，32011530074)、国家重点研发计划(2017YFA0605203)和福建省自然科学基金(2019J02016)资助

摘要 瘤棘奈氏虫 (Netzelia tuberspinifera) 是东亚特有种, 属于有壳虫原生动物, 壳体大小约为 $100 \mu \mathrm{m}$. 本文首先在 空间尺度上对中国88个湖库中瘤棘奈氏虫地理分布进行分析，发现瘤棘奈氏虫的分布与纬度、海拔和温度显著相 关, 分布在低纬度、低海拔、高温的亚热带和热带地区. 重点以福建厦门汀溪水库连续 4 年时间序列样品和中国南 方地区28座水库(14个流域)空间样品为基础, 研究瘤棘奈氏虫种群时空变化规律及其影响因子. 结果表明, 汀溪水 库瘤棘奈氏虫种群密度为0 10.7 ind/L, 存在显著的季节变化, 水温和食物(藻类)是主要影响因子, 其中水温的影响 更大. 水温变化范围在 $14.3 \sim 32.1^{\circ} \mathrm{C}$ 之间, 高于 $30^{\circ} \mathrm{C}$ 的水温更适合瘤棘奈氏虫生长繁殖, 因此在夏秋季节种群密度较 高. 空间尺度上, 瘤棘奈氏虫种群密度为0 19.2 ind/L, 主要受地理因子的限制, 随经度、纬度的增加而降低, 同时食 物(藻类)、电导率和硝态氮对种群密度也存在显著影响。在形态方面, 壳口直径是决定瘤棘奈氏虫种群在季节间 (33.5 68.2 $\mu \mathrm{m})$ 和流域间 $(33.5 \sim 73.6 \mu \mathrm{m})$ 形态差异的主要特征; 食物(藻类)可能是影响汀溪水库不同季节壳口直径 差异的主要因子, 而不同流域间种群壳口直径的差异主要受食物(藻类)、总碳和浊度等生态因子的影响. 本研究 揭示了瘤棘奈氏虫集合种群的时空差异性, 加深了对有壳虫种群地理分布和多样性的认知, 可为水库生态评价与 生物多样性保护提供参考.

关键词有壳虫, 瘤棘奈氏虫, 地理分布, 时间变化, 种群密度, 形态特征

有壳虫(testate amoebae)是一类单细胞原生动物, 广泛分布于淡水、土壤、苔藓等多种生境, 对环境变 化敏感, 其壳体在沉积物中可以长期保存, 能够很好地 记录环境变化, 因此近年来越来越多地应用于古气候 和古环境的重建, 以及环境污染的生物指示 ${ }^{[1 \sim]}$. 有壳 虫在生物地球化学循环和能量流动中发挥着重要作 用 ${ }^{[5-9]}$. 全球已经描述的有壳虫形态种已超过 2000 种 ${ }^{[6]}$. 通过对内陆水体(湖泊水库)的调查发现, 中国拥有丰富
多样的有壳虫资源, 包括东亚特有物种 ${ }^{[3,7,10]}$. 然而, 近 年来水体富营养化的加剧一定程度上造成了局部有壳 虫物种多样性的下降 ${ }^{[3,4]}$. 目前, 生物多样性的保护和可 持续利用已成为当前国际研究的热点 ${ }^{[11]}$, 因此对东亚 特有种进行系统的种群生态学研究是十分迫切和必 要的.

瘤棘奈氏虫(Netzelia tuberspinifera) 是东亚特有有 壳虫, 最初被描述为瘤棘砂壳虫(Difflugia tuberspini-

引用格式: 王文平, 高肖飞, 陈辉煌, 等. 中国瘤棘奈氏虫种群密度和形态特征的时空差异及其影响因子. 科学通报, 2022, 67: 85-98 Wang W P, Gao X F, Chen H H, et al. Spatial-temporal variation of Netzelia tuberspinifera population density and morphometric characteristics in China and its driving factors (in Chinese). Chin Sci Bull, 2022, 67: 85-98, doi: 10.1360/TB-2021-0587 
fera $)^{[7]}$. Gomaa等人 ${ }^{[12,13]}$ 根据 $18 \mathrm{~S}$ rRNA基因序列与壳体 特征将其转移到奈氏虫属(Netzelia). 瘤棘奈氏虫广泛 分布于中国南方水库 ${ }^{[7,14 ~ 17]}$. 胡东利等人 ${ }^{[18]}$ 在中国贵州 乌江渡首次发现该物种, 但未发现活虫体, 均为空的壳 体. 杨军等人 ${ }^{[7,8]}$ 在长江中游水库发现大量瘤棘奈氏虫 的活体, 对其进行了较全面的壳体和细胞形态描述, 并 利用 X射线能谱仪分析了湖北木兰湖(夏家寺水库)瘤 棘奈氏虫壳体元素的组成. 结果发现, 构成壳体的元素 主要是 $\mathrm{Si}$, 其次是 $\mathrm{Ca}$ 和 $\mathrm{Al}$, 还有其他微量元素. Anderson $^{[19]} 、$ Ogden和Meisterfeld ${ }^{[20]}$ 的研究发现, 砂壳虫属、 奈氏虫属有壳虫喜食绿藻和硅藻等藻类. Han等人 ${ }^{[15]}$ 和 王丽娜等人 ${ }^{[21]}$ 发现，瘤棘奈氏虫能够捕食多细胞后生 动物, 尤其是轮虫和桡足类. 研究表明, 同一种有壳虫 在不同生境下也可以形成具有一定形态差异的种 群 $^{[22]}$, 其形态特征与环境因子密切相关 ${ }^{[23,24]}$. 刘乐冕等 人 $^{[14]}$ 比较长江流域和珠江流域瘤棘奈氏虫种群发现, 不同种群之间存在显著的形态差异. 但截至目前, 仍然 缺乏对中国不同流域瘤棘奈氏虫种群密度和形态特征 时空分布及其影响因子的深人研究.

结合前期研究, 我们首先分析了全国 88 个湖库瘤 棘奈氏虫分布规律, 发现瘤棘奈氏虫的分布受纬度、
海拔和温度的显著影响(图1, 表S1). 本文重点研究了 福建厦门汀溪水库连续4年(2016 2019年)时间序列样 品与中国南方28座亚热带和热带水库(14个流域)空间 样品中瘤棘奈氏虫种群密度和形态特征的变化, 并探 讨了引起这些时空变化的关键因子.

\section{1 材料方法}

\section{1 瘤棘奈氏虫地理分布数据}

通过收集中国湖泊和水库有壳虫地理分布信 息 $^{[3,4,7,14,25]}$, 结合本研究对中国南方 28 座水库瘤棘奈氏 虫调查结果, 梳理汇总出 88 个湖泊和水库中瘤棘奈氏 虫的地理分布情况. 根据是否检测出瘤棘奈氏虫, 划分 为有虫体、无虫体两大类湖库(图1, 表 $\mathrm{S} 1)$.

\section{2 水库样品采集}

本研究采集了中国南方 28 座水库(隶属14个流域, 具体水库信息见表1)的瘤棘奈氏虫样品. 采样时间为夏 季, 分别是2018年7 8月和2020年8月. 采集水库表层水 体瘤棘奈氏虫的定量样品和定性样品, 采样频次均为 1 次. 对福建省厦门市汀溪水库表层水体进行了连续 4 年

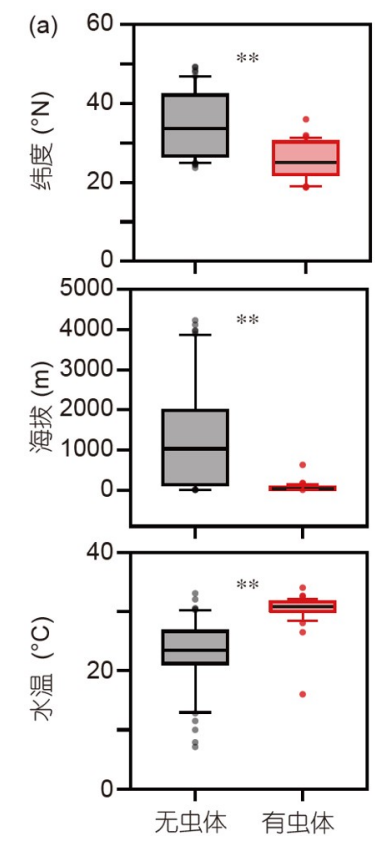

(b)
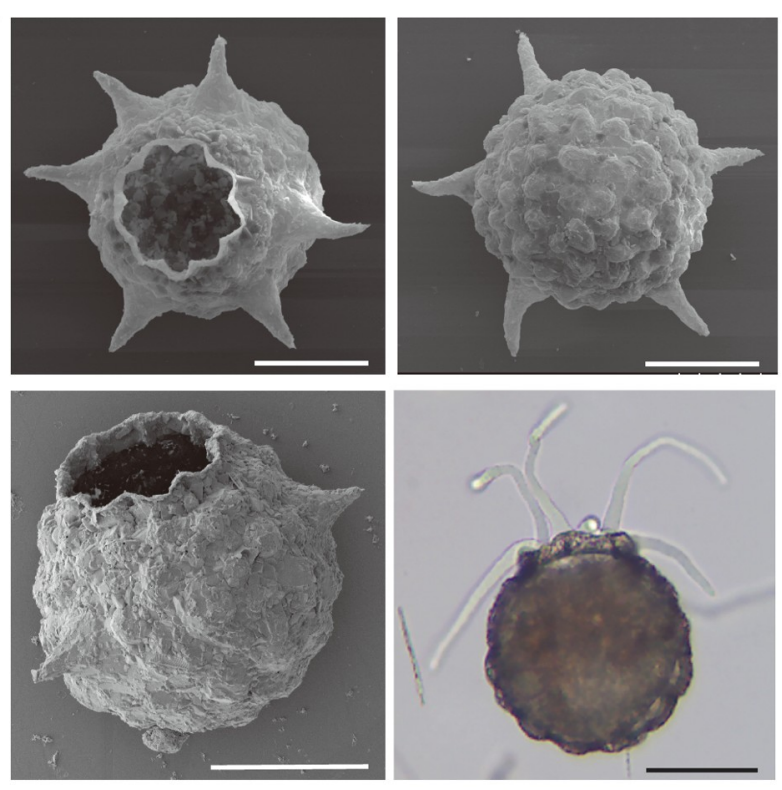

图 1 中国88湖库中瘤棘奈氏虫的分布. (a) 无虫体站位 $(n=50)$ 和有虫体站位 $(n=38)$ 间纬度、海拔和水温的比较. (b) 瘤棘奈氏虫照片依次是虫 体口面观、背面观、侧面观(扫描电子显微镜照片), 以及显示伪足的活体照片(光学显微镜照片), 标尺为 $50 \mu \mathrm{m}$. 湖库的详细信息见表 $\mathrm{S} 1$

Figure 1 Distribution of Netzelia tuberspinifera population in 88 lakes and reservoirs from China. (a) The significant differences of latitude, elevation and temperature between waterbodies without $(n=50)$ and with $(n=38) N$. tuberspinifera. (b) The scanning electron microscope and light microscope photographs of $N$. tuberspinifera showing the aperture, bottom, side and pseudopodia, respectively. Scale bar, $50 \mu \mathrm{m}$. The information of 88 lakes and reservoirs is presented in Table S1 
表 1 中国南方地区采样水库基本信息和瘤棘奈氏虫样本数

Table 1 Basic information of sampling reservoirs and specimen number of N. tuberspinifera in southern China

\begin{tabular}{|c|c|c|c|c|c|c|c|}
\hline 水库编号 & 水库名称 & 采样时间 & 经度 $\left({ }^{\circ} \mathrm{E}\right)$ & 纬度 $\left({ }^{\circ} \mathrm{N}\right)$ & 样本数量 ${ }^{a)}$ & 营养状态指数 & 流域 \\
\hline MLH & 木兰湖 & 2020年8月 13 日 & 114.48 & 31.09 & 101 & 63.12 & 长江 \\
\hline DH & 东湖 & 2020年8月 16日 & 114.41 & 30.55 & 54 & 72.55 & 长江 \\
\hline $\mathrm{NSH}$ & 牛山湖 & 2020年8月 14 日 & 114.54 & 30.33 & 101 & 62.98 & 长江 \\
\hline LZH & 梁子湖 & 2020年8月 15 日 & 114.53 & 30.23 & 180 & 66.67 & 长江 \\
\hline $\mathrm{XH}$ & 西湖 & 2018年8月3 4日 & 120.14 & 30.24 & - & 63.99 & 钱塘江 \\
\hline $\mathrm{DQH}$ & 东钱湖 & 2018年8月6日 & 121.66 & 29.76 & - & 65.17 & 角江 \\
\hline QDH & 千岛湖 & 2018年8月1 3日 & 118.97 & 29.60 & 82 & 48.99 & 钱塘江 \\
\hline HJ & 横锦水库 & 2018年8月 10日 & 120.48 & 29.24 & 60 & 43.07 & 钱塘江 \\
\hline QD & 桥墩水库 & 2018年8月9日 & 120.30 & 27.48 & - & 53.35 & 鳌江 \\
\hline NX & 南溪水库 & 2018年8月 8日 & 120.12 & 27.35 & - & 51.82 & 交溪 \\
\hline SSLJH & 三十六脚湖水库 & 2018年7月 14日 & 119.76 & 25.47 & 21 & 61.25 & 三十六脚湖 \\
\hline $\mathrm{DZ}$ & 东圳水库 & 2018年7月 13日 & 118.95 & 25.48 & 50 & 65.42 & 木兰溪 \\
\hline SM & 山美水库 & 2018年7月9日 & 118.43 & 25.19 & 60 & 54.39 & 晋江 \\
\hline $\mathrm{TX}$ & 汀溪水库 & 2018年8月27日 & 118.14 & 24.80 & 431 & 56.40 & 东西溪 \\
\hline $\mathrm{XFJ}$ & 新丰江水库 & 2018年7月 18 日 & 114.57 & 23.79 & 60 & 32.36 & 珠江 \\
\hline LXH & 流溪河水库 & 2018年7月21日 & 113.79 & 23.76 & 60 & 39.78 & 珠江 \\
\hline DSH & 大沙河水库 & 2018年7月22日 & 112.40 & 22.54 & 50 & 63.59 & 珠江 \\
\hline DJS & 大镜山水库 & 2018年7月20日 & 113.55 & 22.30 & 30 & 65.00 & 珠江 \\
\hline $\mathrm{GZ}$ & 高州水库 & 2018年7月23日 & 111.05 & 22.05 & 61 & 48.64 & 珠江 \\
\hline WSJ & 旺盛江水库 & 2018年8月 20日 & 109.61 & 21.92 & 30 & 55.85 & 南流江 \\
\hline $\mathrm{HCJ}$ & 洪潮江水库 & 2018年8月 18 日 & 109.15 & 21.83 & 40 & 62.02 & 南流江 \\
\hline SK & 石康水库 & 2918年8月19日 & 109.35 & 21.76 & 10 & 64.19 & 南流江 \\
\hline QSJ & 清水江水库 & 2018年8月19日 & 109.28 & 21.69 & 30 & 66.78 & 南流江 \\
\hline NWL & 牛尾岭水库 & 2018年8月19日 & 109.24 & 21.60 & 30 & 65.98 & 南流江 \\
\hline DGB & 大广坝水库 & 2018年8月24日 & 109.02 & 18.96 & 30 & 51.46 & 昌化江 \\
\hline NLL & 牛路岭水库 & 2018年8月23日 & 110.15 & 18.96 & 30 & 53.62 & 万泉河 \\
\hline WN & 万宁水库 & 2018年8月23日 & 110.31 & 18.78 & 30 & 55.44 & 太阳河 \\
\hline BT & 碑头水库 & 2018年8月22日 & 110.27 & 18.72 & 30 & 57.83 & 太阳河 \\
\hline
\end{tabular}

a) “一”表示未分离到足够的样本

(2016 2019年)样品的采集，每次样品采集时间间隔约 为 $10 \mathrm{~d}$.

定量样品用于瘤棘奈氏虫种群密度估算，定性样 品用于分离、检测瘤棘奈氏虫壳体特征值. 定量样品 和定性样品均来自表层水体. 本研究中绝大多数个体 为活体, 虫体具有伪足. 定量样品采集时, 使用 25 \#浮游 生物网(孔径为 $64 \mu \mathrm{m}$ )过滤 $60 \mathrm{~L}$ 体积的表层水. 直接使 用 25 \#浮游生物网采集定性样品, 在水体表层 $(3 \mathrm{~m}$ 以 浅)水平来回拖拽捞取样品，一般拖网 20 次左右，富集 浓缩后收集到 $50 \mathrm{~mL}$ 的样品瓶中，在 $4 \mathrm{~h}$ 内带回实验室
对样品进行分离、鉴定和观测.

\section{3 环境因子测定}

现场用便携式测深仪SM-5(Speedtech Instruments, Great Falls, VA, 美国)测量采样站位的水深; 利用Secchi 圆盘测定水体透明度, 真光层深度为透明度的 2.7 倍 ${ }^{[26]}$. 使用多参数水质分析仪Hydrolab DS5(Hach Company, Loveland, $\mathrm{CO}$, 美国)测定水温、 $\mathrm{pH}$ 、溶解氧、浊度、 总叶绿素 $a$ 、电导率和氧化还原电位. 使用Phyto-PAM 浮游植物分析仪(Heinz Walz GmbH, Effeltrich, 德国) 
检测蓝藻、绿藻和硅藻叶绿素含量. 总碳(total carbon, $\mathrm{TC}$ )、总有机碳(total organic carbon, TOC)、总氮(total nitrogen, TN)、氨氮( ammonium nitrogen, $\left.\mathrm{NH}_{4}-\mathrm{N}\right)$ 、硝 态氮(nitrate nitrogen, $\mathrm{NO}_{3}-\mathrm{N}$ )、亚硝态氮(nitrite nitrogen, $\mathrm{NO}_{2}-\mathrm{N}$ )、总磷(total phosphorus, TP) 和磷酸盐 (phosphate phosphorus, $\mathrm{PO}_{4}-\mathrm{P}$ ) 的测定依据标准的水质 监测方法 ${ }^{[27,28]}$. 最后, 根据水体叶绿素 $a(\mu \mathrm{g} / \mathrm{L})$ 、透明度 $(\mathrm{m})$ 和总磷 $(\mu \mathrm{g} / \mathrm{L})$ 计算水库的 Carlson营养状态指数 (trophic state index, TSI), 其中水体叶绿素 $a$ 采用丙酮萃 取法与分光光度计分析法获得 ${ }^{[25]}$.

\section{4 瘤棘奈氏虫密度和形态特征分析}

使用倒置显微镜检测定量样品瘤棘奈氏虫的种群 密度. 根据Yang 等人 ${ }^{[7]}$ 和刘乐冕等人 ${ }^{[14]}$ 的研究, 选择 5 个形态特征值进行测量或计数, 分别是壳高、壳直 径、壳口直径、壳刺长和壳刺数. 在 28 座水库中, 24座 水库检测到足够多的瘤棘奈氏虫, 其余4座水库极少或 未发现虫体. 因此, 选择瘤棘奈氏虫充足的 11 个流域 24 座水库开展进一步分析, 总计对 1260 个虫体进行了形 态特征统计. 在时间尺度上, 我们观测分析汀溪水库 2016 2019年瘤棘奈氏虫种群密度的变化, 并分离观测 了 401 个虫体的形态特征.

\section{5 统计分析}

采用主成分分析(principal component analysis, $\mathrm{PCA}$ )对瘤棘奈氏虫形态特征参数进行了可视化, 在 $\mathrm{R}$ 软件(version 4.0.0)的“ggrepel”程序包中进行. 利用相 似性分析(analysis of similarity, ANOSIM)考察不同流 域之间和不同季节之间的种群形态差异; Global R值表 征不同组之间的分离程度, 1 表示完全分离、 0 表示没 有分离(完全相同). 使用随机森林分类模型分析瘤棘奈 氏虫形态特征对组间差异贡献的重要性. 该重要性针 对每棵树的精度, 并在整个森林(5000个随机树)中取平 均值. 该分析是利用 R软件(version 4.0.0)中的“ randomForest”程序包进行 ${ }^{[29]}$.

使用随机森林回归分析(random forest regression analysis)解析影响种群密度和种群形态特征的关键预 测因子. 均方误差(mean square error, MSE)值越高, 说 明该变量重要性越高. 通过5000次响应变量的置换, 应 用 R软件(version 4.0.0)“A3”程序包计算模型的显著性 和交叉验证的 $R^{2}$ 值 ${ }^{[30]}$. 我们同时使用“rfPermute”程序 包评估每个预测变量的显著性, 随后使用层次划分 (hierarchical partitioning analysis)分析了可能影响瘤棘 奈氏虫种群密度和形态特征的关键因子. 该分析利用 $\mathrm{R}$ 软件中的“hier.part”程序包进行, 能够确定最可能的因 果关系, 并且有效去除或减弱变量之间的多重共线性, 但在使用该分析时需要注意变量的数量尽量小于 9 个, 当变量数大于 9 个时, 可能会存在模块计算时的潜在误 差 $^{[31]}$.

通过偏最小二乘路径模型(partial least squares path models, PLS-PM)分析, 进一步预测理化因子、营养 盐、浮游藻类对瘤棘奈氏虫种群密度或壳体形态的直 接和间接影响 ${ }^{[30,32]}$. 该分析在R软件(version 4.0.0)中通 过“plspm”包进行, 该模型可以评估多个变量之间的复 杂因果关系包括间接和直接效应. 路径系数 $\left(R^{2}\right)$ 反映了 变量之间线性关系的方向和强度, 而预测变量和响应 变量之间相乘的路径系数则显示出间接影响的强度. 拟合度指数(goodness of fit index, GOF)用于评估模型 的预测性能, 数值越大, 模型预测效果越好 ${ }^{[33]}$.

\section{2 结果}

\section{1 瘤棘奈氏虫种群密度的时空差异及其与环境因 子的关系}

时间尺度上, 汀溪水库中瘤棘奈氏虫种群密度存 在显著的季节差异, 夏季和秋季种群密度相对较高, 最 高可达到 $10.7 \mathrm{ind} / \mathrm{L}$, 冬季和春季种群密度很低, 甚至虫 体完全消失(图2(a)). 通过随机森林回归分析显示, 水温 和食物(藻类, 尤其是绿藻)是瘤棘奈氏虫种群密度的显 著预测因子(图3(a)). 层次划分分析结果显示, 水温对种 群密度相对解释量高于食物, 达到78.8\%(图3(a)). 汀溪 水库 4 年期间表层水温变化范围为 $14.3 \sim 32.1^{\circ} \mathrm{C}$, 路径分 析(PLS-PM)结果表明, 水温对瘤棘奈氏虫种群密度具 有显著、正向的直接影响(图4(a)).

在 28 座水库中, 瘤棘奈氏虫种群密度变化范围为 0 19.2 ind/L, 其分布在经度和纬度上均存在一定规律 性变化(图2(b)), 相对于高经度、高纬度水库, 低经度、 低纬度水库中瘤棘奈氏虫种群密度更高. 随机森林回 归分析结果表明, 经度、纬度、电导率、叶绿素 $a$ 、硝 态氮和悬浮颗粒与瘤棘奈氏虫种群密度的流域分布显 著相关(图3(b)). 层次划分分析显示, 瘤棘奈氏虫种群密 度受经度和纬度的影响相对更大(图3(b)). 路径分析 (PLS-PM)结果表明, 经度、纬度对瘤棘奈氏虫种群密 度存在显著、负向的直接和间接影响(图4(b)). 

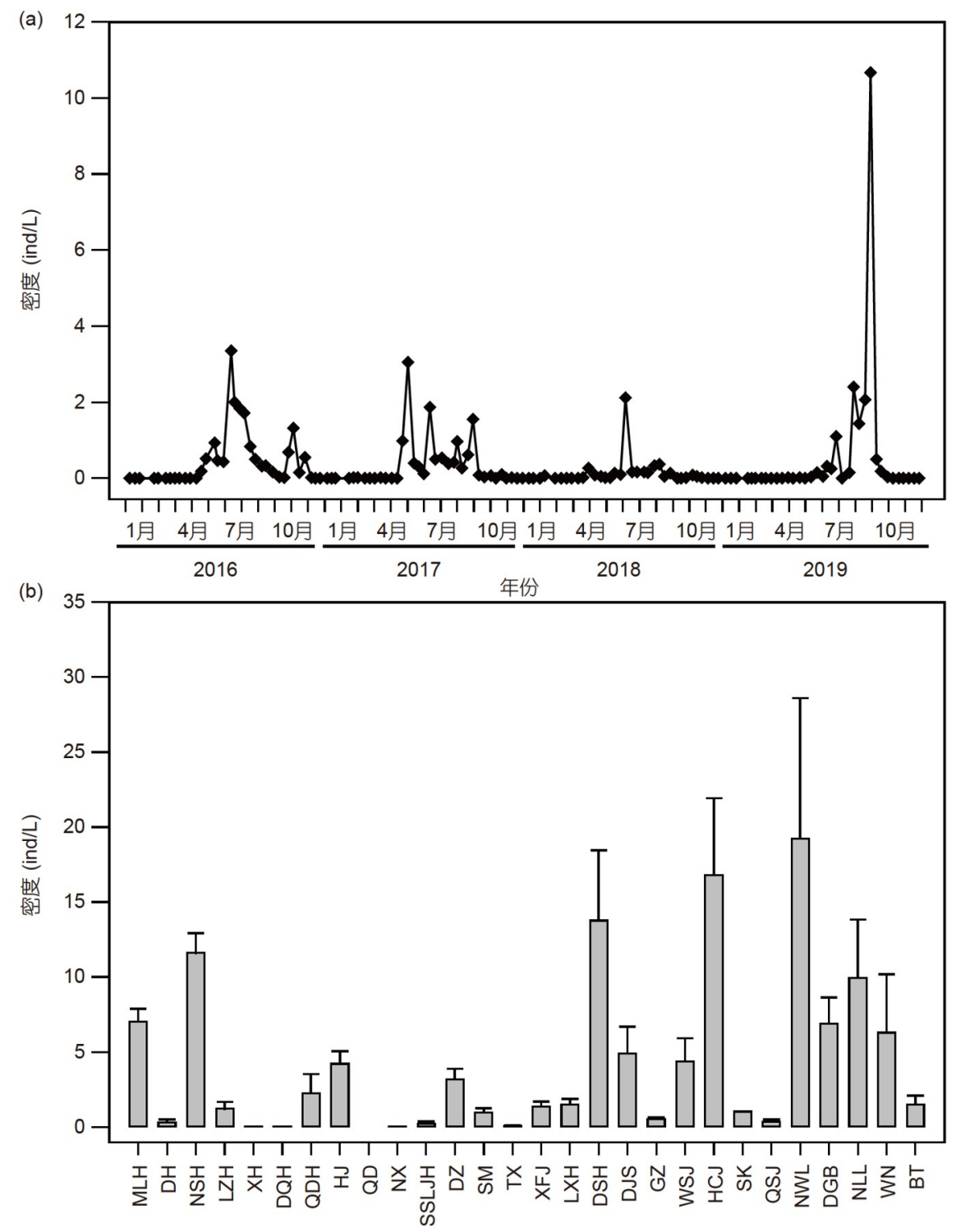

图 2 中国亚热带和热带水库中瘤棘奈氏虫种群密度的时空动态. (a) 厦门汀溪水库瘤棘奈氏虫种密度的时间动态(2016 2019年). (b) 中国南方 28座亚热带和热带水库瘤棘奈氏虫密度的空间动态. 水库缩写信息见表1

Figure 2 Spatial-temporal dynamics of $N$. tuberspinifera population from subtropical or tropical reservoirs of China. (a) Temporal dynamics of $N$. tuberspinifera population in Tingxi Reservoir of Xiamen City (2016-2019). (b) Spatial distributions of N. tuberspinifera from 28 subtropical or tropical reservoirs, southern China. For reservoir information see Table 1

\section{2 瘤棘奈氏虫种群形态特征的时空差异及其与环 境因子的关系}

在时间尺度上, PCA结果显示, 汀溪水库中瘤棘奈 氏虫种群形态存在显著的季节差异(图5(a)), 夏季种群 形态的多元分散指数较低, ANOSIM检验也显示夏季 种群形态与其他季节呈现显著差异(表 $2, P<0.01)$. 随 机森林分类分析结果表明, 壳口直径差异(壳口直径范 围: $33.5 \sim 68.2 \mu \mathrm{m})$ 对种群形态季节性分化的贡献最大 (图5(c)); 随机森林回归分析预测发现, 食物(藻类, 主要是 硅藻和绿藻)和浊度与壳口直径差异显著相关(图6(a)). 层次划分分析显示，瘤棘奈氏虫壳口直径的差异受食 物(藻类)的影响相对较大, 尤其是硅藻(图6(a)). 路径分 析(PLS-PM)结果表明, 食物(藻类)对瘤棘奈氏虫种群壳 口直径季节变化存在显著、正向的直接影响(图7(a)).

在空间尺度上, PCA结果显示, 瘤棘奈氏虫种群形 态在11个流域(24座水库)间存在一定差异, 尤其是长江 流域与其他流域之间瘤棘奈氏虫形态差异最明显(图5 

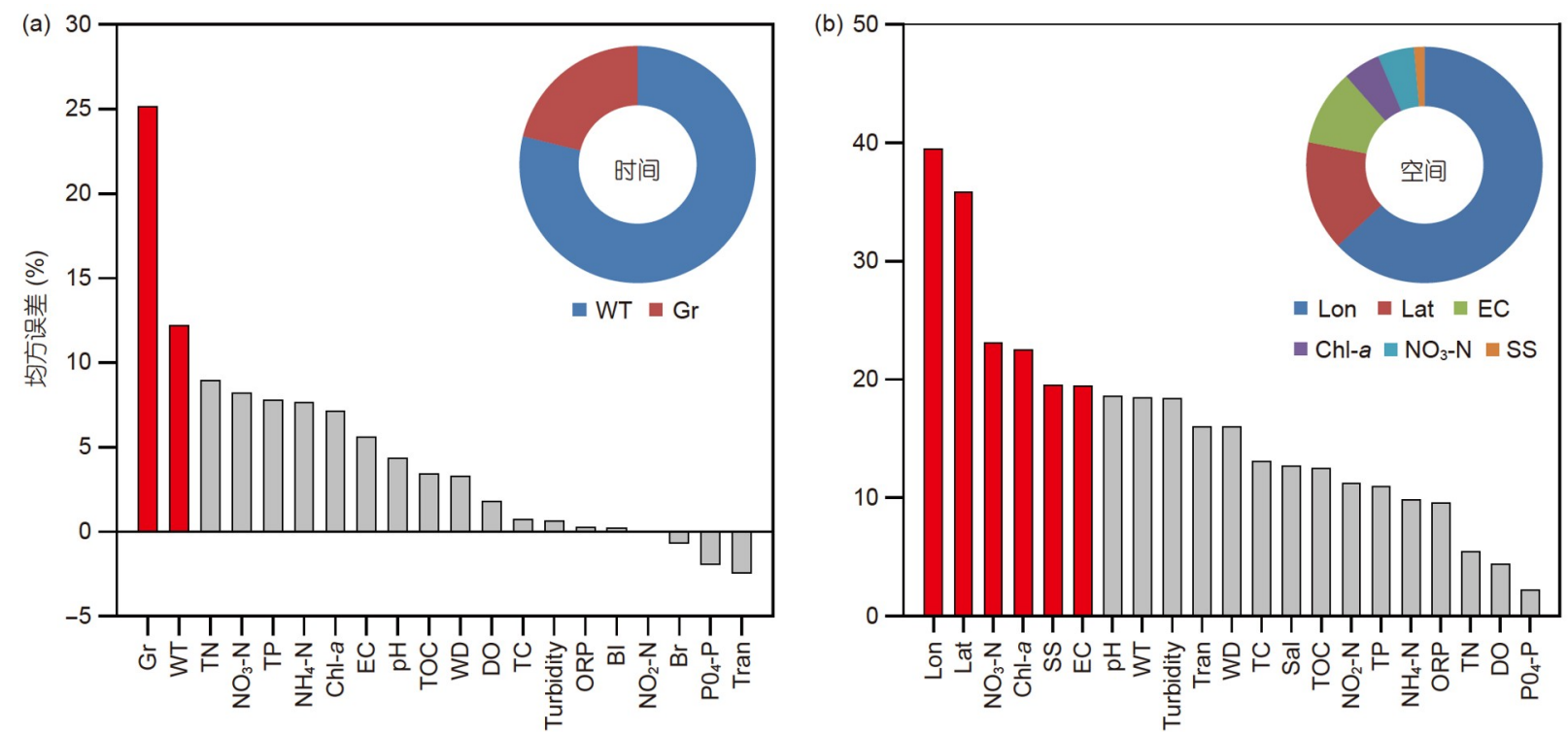

图 3 随机森林回归分析解析水库环境因子与瘤棘奈氏虫种群密度时空变化的关系. (a) 汀溪水库连续4年瘤棘奈氏虫种群; (b) 中国南方28座 水库瘤棘奈氏虫种群. 红色柱子为显著因子 $(P<0.05)$. 其中均方误差(MSE)的值越高代表该因子对瘤棘奈氏虫种群密度变化的驱动重要性越 高. 环形饼图表示关键因子对瘤棘奈氏虫密度变化独立影响的相对解释量. Lon: 经度; Lat: 纬度; WD: 水深; Trans: 透明度; WT: 水温; DO: 溶解

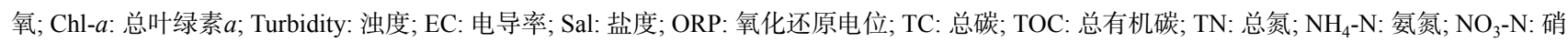
态氮; $\mathrm{NO}_{2}-\mathrm{N}$ : 亚硝态氮; TP: 总磷; $\mathrm{PO}_{4}-\mathrm{P}$ : 磷酸盐; $\mathrm{SS}$ : 悬浮颗粒; $\mathrm{Gr}$ : 绿藻叶绿素; $\mathrm{Bl}$ : 蓝藻叶绿素; $\mathrm{Br}$ : 硅藻叶绿素

Figure 3 Random forest regression analysis showing the relationship between environmental factors and $N$. tuberspinifera population density across space and time. (a) N. tuberspinifera in Tingxi Reservoir over four years (2016-2019); (b) N. tuberspinifera in 28 reservoirs of southern China. The red columns represent significant factors $(P<0.05)$. The higher value of MSE indicates greater importance in explaining the density of $N$. tuberspinifera population. Circular pie chart based on hierarchical partitioning analysis showing the independent effects of each of significant factors for density of $N$. tuberspinifera population. Lon: Longitude; Lat: Latitude; WD: Water depth; Trans: Transparency; WT: Water temperature; DO: Dissolved oxygen; Chl$a$ : Total chlorophyll- $a$; EC: Electrical conductivity; Sal: Salinity; ORP: Oxidation-reduction potential; TC: Total carbon; TOC: Total organic carbon; $\mathrm{TN}$ : Total nitrogen; $\mathrm{NH}_{4}-\mathrm{N}$ : Ammonium nitrogen; $\mathrm{NO}_{3}-\mathrm{N}$ : Nitrate nitrogen; $\mathrm{NO}_{2}-\mathrm{N}$ : Nitrite nitrogen; TP: Total phosphorus; $\mathrm{PO}_{4}-\mathrm{P}$ : Phosphate phosphorus; SS: Suspended solid; Gr: Chlorophyta; Bl: Cyanophyta; Br: Bacillariophyta

(b)). ANOSIM检验也支持长江流域种群区别于其他流 域的结果(表3, $P<0.01$ ). 有趣的是, 壳口直径差异同样 是造成不同流域瘤棘奈氏虫种群间形态差异的主要因 素(图5(d)), 长江流域瘤棘奈氏虫种群壳口直径(均值 为 $67.3 \mu \mathrm{m}$, 范围: $50.2 \sim 73.6 \mu \mathrm{m}$ ) 明显大于其他流域 $(42.2 \mu \mathrm{m}$, 范围: 33.5 58.5 $\mu \mathrm{m})$. 总碳、叶绿素 $a$ 、浊 度、纬度和电导率是影响瘤棘奈氏虫种群壳口直径差 异的关键因子. 层次划分结果显示, 总碳、叶绿素 $a$ 、 浊度和纬度对壳口直径差异独立解释量相差不大, 且 均高于电导率(图6(b)). 此外, 路径分析(PLS-PM)结果 显示，不同流域间瘤棘奈氏虫种群壳口直径差异受到 食物(藻类)显著的直接影响, 同时经度、纬度通过影响 食物进而对壳口直径存在显著的间接影响(图7(b)).

\section{3 讨论}

瘤棘奈氏虫的形态十分独特, 很容易准确无误地 识别鉴定, 目前仅发现于中国境内; 在有壳虫调查研究
相对较多的欧洲和北美地区均未发现该物种，因此瘤 棘奈氏虫被称为东亚特有种 ${ }^{[7,12,14]}$. 我们通过对中国 88 个湖库瘤棘奈氏虫地理分布的总结发现, 瘤棘奈氏虫 分布与纬度、海拔和温度密切相关, 主要分布在低纬 度、低海拔、高温度的亚热带和热带地区(图1), 特别 在中营养和富营养化初期的水体密度较高 ${ }^{[7,14,17]}$. 对于 高纬度湖泊(东平湖)零星出现瘤棘奈氏虫的原因, 我们 推测可能是由于人类活动特别是南水北调工程实施, 将长江流域种群引人北方, 进而引起物种向北扩散. 本 研究通过对汀溪水库连续4年和中国亚热带与热带地 区14个流域28座水库瘤棘奈氏虫种群的研究, 比较分 析了瘤棘奈氏虫种群密度和形态特征时空差异及其关 键影响因子.

\section{1 水温和食物是影响瘤棘奈氏虫种群密度时间变 化的关键因子}

刘乐冕等人 ${ }^{[14]}$ 发现瘤棘奈氏虫在亚热带水库水体 

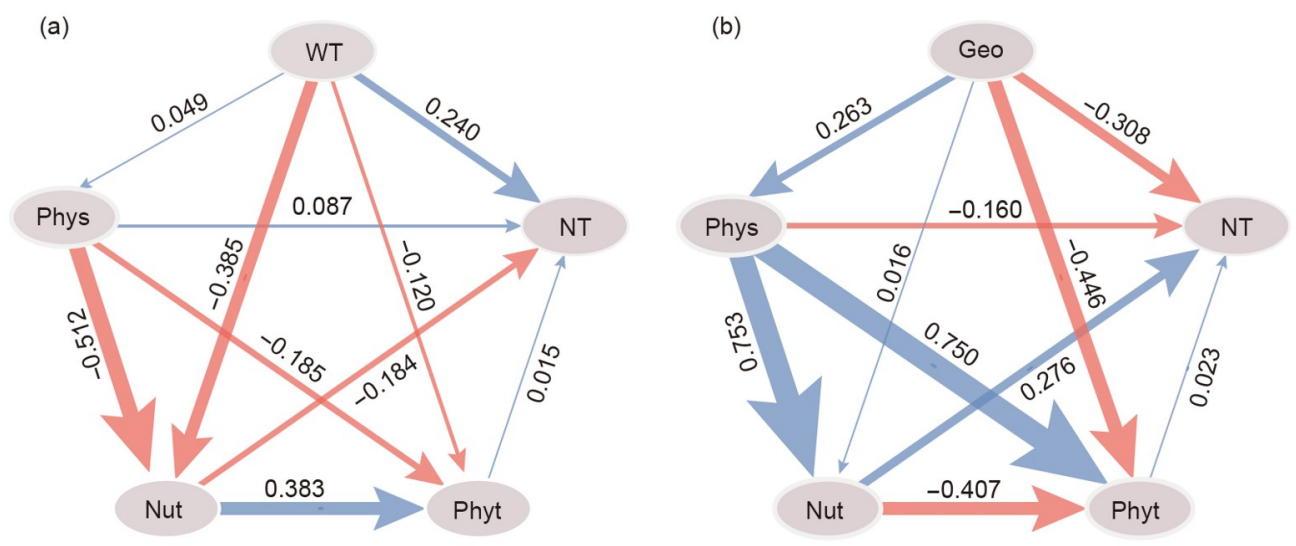

图 4 水温/地理因子、理化因子、营养盐和浮游藻类对瘤棘奈氏虫种群密度的直接和间接影响. 蓝色和红色线条分别代表正和负的影响. 线 条的粗细代表路径系数. 模型拟合度GOF值在汀溪水库(a)和28座水库(b)中分别为 0.397 和0.441. (a) 中WT: 水温; Phys: 水深、透明度; Nut: 总 氮、氨氮、硝态氮、总磷; Phyt: 硅藻叶绿素、绿藻叶绿素; NT: 汀溪水库瘤棘奈氏虫种群密度. (b) 中Geo: 经度、纬度; Phys: 水深、悬浮颗 粒、透明度、浊度、电导率、盐度; Nut: 总碳、总有机碳、氨氮、总磷; Phyt: 藻类总叶绿素 $a$; NT: 28座水库瘤棘奈氏虫种群密度

Figure 4 The direct and indirect effects of water temperature or geographical factors, physico-chemical factors, nutrients, and phytoplankton on $N$. tuberspinifera population density. The blue and red lines represent positive and negative effects, respectively. The thickness of the line represents the value of the path coefficient. Goodness of fit index was 0.397 and 0.441 for Tingxi Reservoir (a) and 28 reservoirs (b), respectively. WT: Water temperature; Phys: Water depth, transparency; Nut: Total nitrogen, ammonium nitrogen, nitrate nitrogen, total phosphorus; Phyt: Chlorophyll- $a$ of Bacillariophyta and chlorophyll- $a$ of Chlorophyta; NT: The density of $N$. tuberspinifera population in (a). Geo: Longitude, latitude; Phys: Water depth, suspended solid, transparency, turbidity, electrical conductivity, salinity; Nut: Total carbon, total organic carbon, ammonium nitrogen, total phosphorus; Phyt: Total chlorophyll- $a$ of phytoplankton; NT: The density of $N$. tuberspinifera population from 28 reservoirs in (b)

中的分布具有明显的季节性, 夏季和秋季种群密度较 高, 推测这种季节性变化规律可能与水温有关, 但尚无 系统的研究验证. 本研究通过对厦门汀溪水库中瘤棘 奈氏虫连续4年的观测研究, 进一步证实了这一推论. 在汀溪水库, 瘤棘奈氏虫种群密度表现出显著的季节 性变化(图2(a)), 种群密度的季节性变化主要受到水温 和食物(藻类, 尤其是绿藻)的影响, 其中水温的影响大 于食物(图3(a)). 水温的升高或降低能够直接显著影响 浮游生物(包括瘤棘奈氏虫和藻类)的生长繁殖 ${ }^{[4,34,35]}$. 夏季和秋季水库水温较高, 瘤棘奈氏虫生长繁殖较快, 一般在7 9月份种群密度达到最高峰; 而在冬季和春季 时水温较低, 瘤棘奈氏虫生长繁殖受到限制, 因此冬季 和春季水体中瘤棘奈氏虫种群密度通常较低, 甚至为 零. 事实上，在冬季水体中很难发现活体瘤棘奈氏虫， 最大的可能是虫体形成包囊, 进人水库沉积物表层进 行越冬.

食物对生物的生长繁殖是必不可少的，瘤棘奈氏 虫不仅可以捕食浮游藻类，Han等人 ${ }^{[15]}$ 和王丽娜等 人 $^{[21]}$ 分别采用显微观察和DNA测序技术发现瘤棘奈氏 虫可以捕食轮虫、枝角类和桡足类等后生浮游动物. 在汀溪水库中, 我们发现, 藻类(尤其是绿藻)对瘤棘奈 氏虫种群密度影响较大, 绿藻是汀溪水库浮游植物中
的优势类群，为瘤棘奈氏虫等原生动物提供了高质量 的食物. 同时, 绿藻还可以被枝角类和桡足类等浮游动 物捕食 ${ }^{[36]}$. 因此, 水体中后生浮游动物的种群波动对瘤 棘奈氏虫的种群密度也必然产生一定影响. 通常在水 库生态系统中还存在鱼类, 鱼类可以通过捕食藻类、 轮虫、枝角类和桡足类等浮游生物跟瘤棘奈氏虫直接 竞争食物 ${ }^{[15,37]}$, 进而影响瘤棘奈氏虫种群密度. 尽管目 前尚无直接证据表明鱼类直接捕食瘤棘奈氏虫, 但是 从瘤棘奈氏虫个体大小方面来看是, 作为单细胞的原 生动物极有可能也会被鱼类直接捕食. 因此, 鱼类可能 通过食物网的下行效应、竞争食物等途径影响瘤棘奈 氏虫的种群密度.

\section{2 瘤棘奈氏虫种群密度随经度、纬度的升高而 降低}

$\mathrm{Ju}$ 等人 ${ }^{[3]}$ 对中国湖库有壳虫群落地理分布格局分 析后发现, 少数有壳虫种类属于广布种, 多数种类分布 受环境地理因素限制，随着纬度的升高有壳虫丰度和 生物量呈显著降低趋势, 并发现海拔是造成纬度差异 的主要因素. 本研究结果表明, 中国南方地区28座水库 的海拔均未超过 $180 \mathrm{~m}$, 属于低海拔水库, 因此海拔对 
(a)

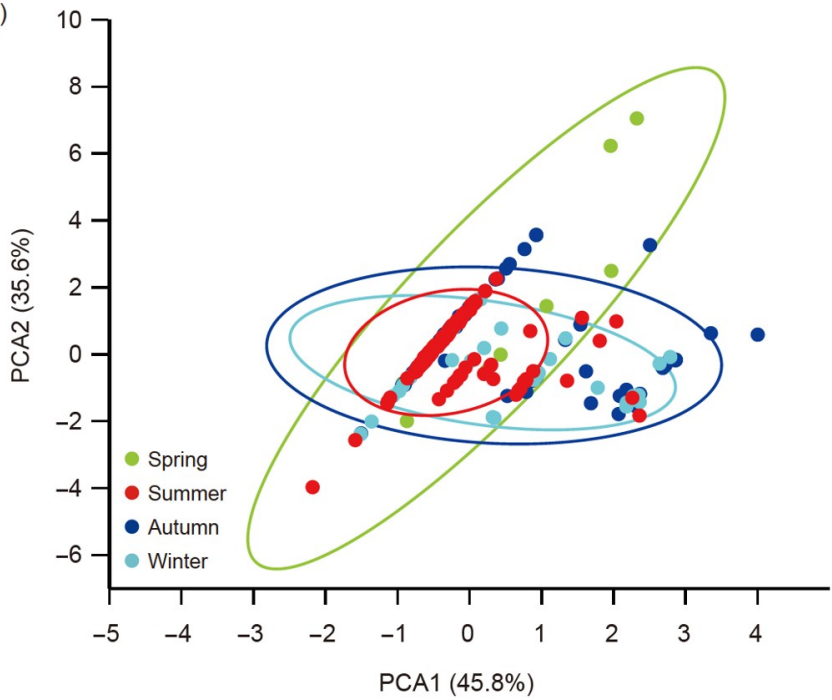

(b)

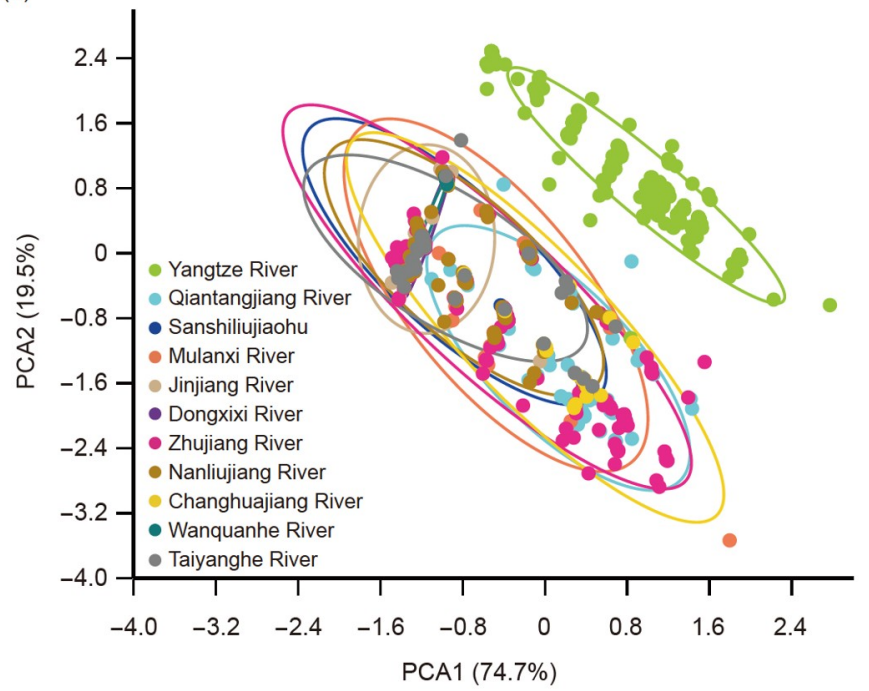

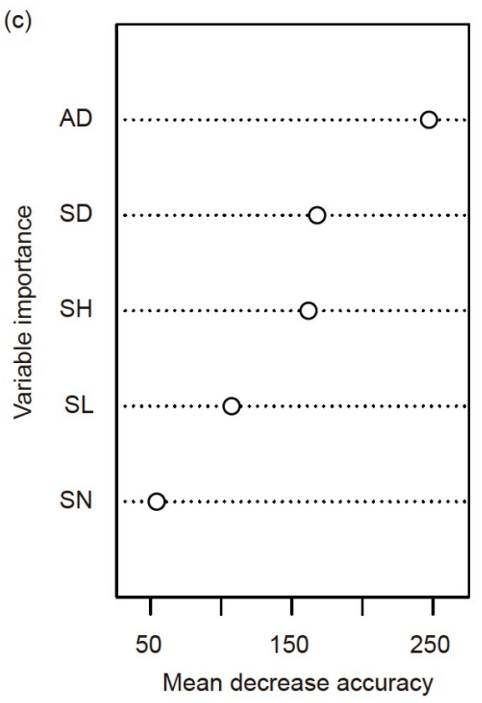

(d)

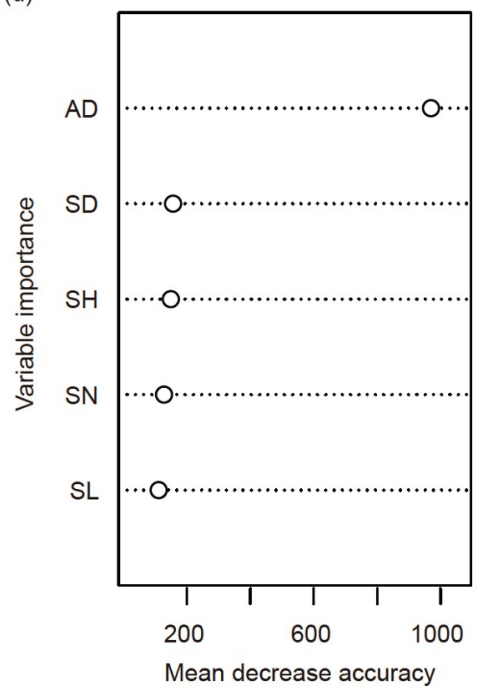

图 5 瘤棘奈氏虫形态特征的时空差异. 主成分分析(PCA)显示瘤棘奈氏虫在汀溪水库中不同季节(a)和11个流域24座水库(b)中形态特征分布. (c) 汀溪水库中瘤棘奈氏虫形态特征对不同季节间差异的贡献度. (d) 瘤棘奈氏虫形态特征对 11 个流域间种群差异的贡献度. AD: 壳口直径; SD: 壳直径; SH: 壳高; SN: 壳刺数; SL: 壳刺长

Figure 5 Spatial-temporal distribution of morphometric characteristics of $N$. tuberspinifera. Principal component analysis (PCA) of N. tuberspinifera morphometric characteristics from different seasons in Tingxi Reservoir (a) and from 11 watersheds (24 reservoirs) (b), respectively. (c) The contributions of morphometric characteristics to temporal difference from different seasons in Tingxi Reservoir. (d) The contributions of morphometric characteristics to spatial difference from 11 watersheds. AD: Aperture diameter; SD: Shell diameter; SH: Shell height; SN: Spine number; SL: Spine length

瘤棘奈氏虫的影响可能不强, 但是瘤棘奈氏虫的种群 密度存在纬度上的递减规律，其中最关键的环境因子 是温度. 此外, 我们发现瘤棘奈氏虫种群密度在经度梯 度上也存在一定的递减分布，从西部区域向东部沿海 地区其密度逐渐降低. 中国东部沿海地区流域内人口 密度相对较高, 对水库水体的人为干扰相对于西部地 区较大 ${ }^{[38,39]}$. 本研究中, 中国东部沿海地区的水库综合
营养指数相对高于西部地区水库. 因此, 我们推测人类 活动导致水库富营养化, 重度富营养化引起的水质恶 化不利于瘤棘奈氏虫生存. 目前, 还有一个不能排除的 可能原因是, 东部水库受人类活动影响较大, 水体中存 在我们未检测的污染物或其他因子 ${ }^{[40,41]}$ ，这些因素对 瘤棘奈氏虫种群密度分布的影响需要进一步的研究.

在28座水库中，其中浙江省桥墩水库未检测到瘤 
表 2 相似性分析(ANOSIM)检验汀溪水库不同季节的瘤棘奈 氏虫种群形态差异 ${ }^{a)}$

Table 2 Analysis of similarity (ANOSIM) statistics testing the difference in morphometric characteristics of $N$. tuberspinifera population from different seasons in Tingxi Reservoir

\begin{tabular}{ccc}
\hline \multirow{2}{*}{ 组间 } & \multicolumn{2}{c}{ 汀溪水库 } \\
\cline { 2 - 3 } & $R$ & $P$ \\
\hline 季节(春、夏、秋、冬) & 0.116 & 0.001 \\
春季 vs. 夏季 & 0.332 & 0.004 \\
春季 vs. 秋季 & 0.074 & 0.185 \\
春季 vs. 冬季 & 0.064 & 0.206 \\
夏季 vs. 秋季 & 0.108 & 0.001 \\
夏季 vs. 冬季 & 0.150 & 0.001 \\
秋季 vs. 冬季 & 0.013 & 0.213 \\
\hline
\end{tabular}

a) 比较分析的形态特征参数包括壳高、壳直径、壳口直径、 壳刺数、壳刺长

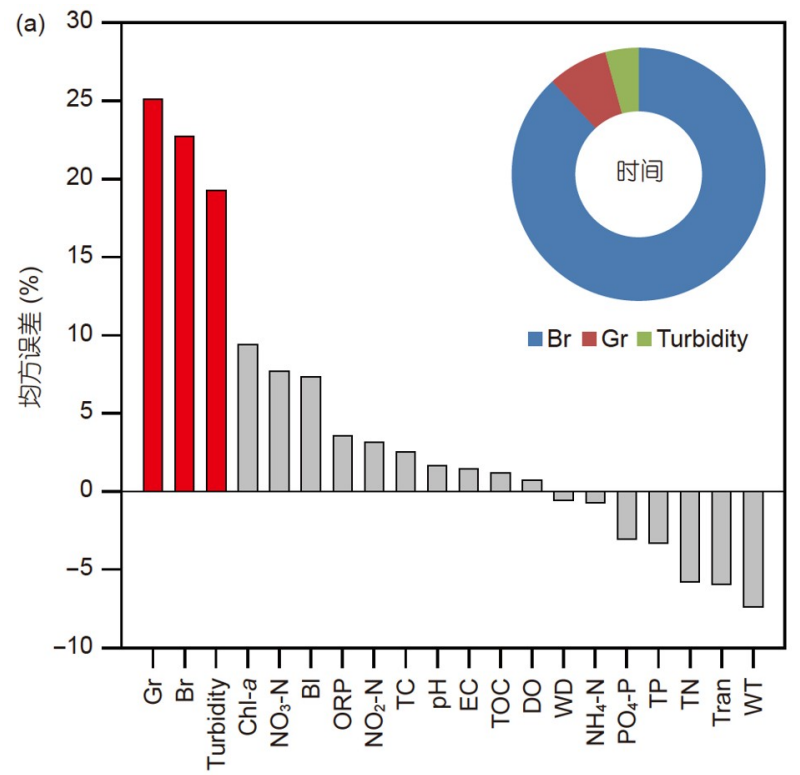

棘奈氏虫，杭州西湖、宁波东钱湖和宁德南溪水库瘤 棘奈氏虫密度非常低(图2(b)). 有壳虫物种多样性沿营 养状态梯度呈现单峰变化趋势，在贫营养水体和重度 富营养水体都不利于有壳虫生存，在中营养水体的多 样性最高 ${ }^{[3,10,24]}$; 瘤棘奈氏虫对水体的富营养化水平也 比较敏感，主要分布于中营养和轻度富营养水体 ${ }^{[14,17]}$ 与其他水体相比，杭州西湖和宁波东钱湖均为我著名 景区, 建有水上乐园或码头, 受人为活动影响较大, 水 体营养水平较高 ${ }^{[42 ~ 44]}$, 因此, 水体富营养化和人为污染 可能是杭州西湖和东钱湖中瘤棘奈氏虫密度较低的原 因. 比较特殊的是, 桥墩水库和南溪水库的人为干扰状 况和水体营养水平与其他高密度瘤棘奈氏虫水库没有 表现出显著的差异. 从地理位置上看, 桥墩水库隶属于 鳌江流域, 该流域尚无瘤棘奈氏虫的报道, 我们推测可 能是由于物种地理扩散过程的限制，也有可能桥墩水 (b)

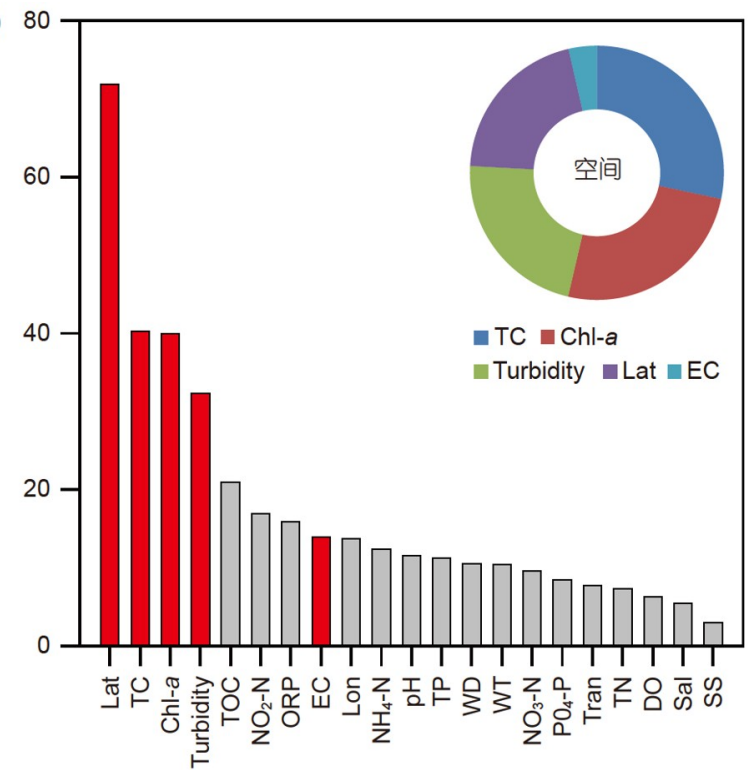

图 6 随机森林回归分析解析水库环境因子与瘤棘奈氏虫壳口直径时空变化的关系. (a) 汀溪水库连续4年瘤棘奈氏虫种群(2016 2019年); (b) 中国24座水库瘤棘奈氏虫种群. 红色柱子为显著因子 $(P<0.05)$. 均方误差的值越高代表该因子对瘤棘奈氏虫壳口直径变化的驱动重要性越高. 层次划分显示了显著因子对汀溪水库不同季节((a)中的环形图)和中国南方 11 个流域24座水库((b)中的环形图)中瘤棘奈氏虫壳口直径变化独立 影响的相对解释量. Lon: 经度; Lat: 纬度; WD: 水深; Trans: 透明度; WT: 水温; DO: 溶解氧; Chl- $a$ : 总叶绿素 $a$; Turbidity: 浊度; EC: 电导率; Sal: 盐度; ORP: 氧化还原电位; TC: 总碳; TOC: 总有机碳; TN: 总氮; $\mathrm{NH}_{4}-\mathrm{N}$ : 氨氮; $\mathrm{NO}_{3}-\mathrm{N}$ : 硝态氮; $\mathrm{NO}_{2}-\mathrm{N}$ : 亚硝态氮; TP: 总磷; $\mathrm{PO}{ }_{4}-\mathrm{P}$ : 磷酸盐; $\mathrm{SS}$ : 悬浮颗粒; $\mathrm{Gr}$ : 绿藻叶绿素; B1: 蓝藻叶绿素; Br: 硅藻叶绿素

Figure 6 Random forest regression analysis showing the relationship between environmental factors and aperture diameter variation of $N$. tuberspinifera population across space and time. (a) N. tuberspinifera in Tingxi Reservoir over four years (2016-2019); (b) N. tuberspinifera in 24 reservoirs of southern China. The red columns represent significant factors $(P<0.05)$. The higher value of MSE indicates greater importance in explaining the aperture diameter variation of $N$. tuberspinifera population. Hierarchical partitioning analysis showing the independent effects of each of significant environmental factors for aperture diameter variation of $N$. tuberspinifera in Tingxi Reservoir from different seasons (donut chart in (a)) and from 11 watersheds (24 reservoirs) (donut chart in (b)), respectively. Lon: Longitude; Lat: Latitude; WD: Water depth; Trans: Transparency; WT: Water temperature; DO: Dissolved oxygen; Chl- $a$ : Chlorophyll- $a$; EC: Electrical conductivity; Sal: Salinity; ORP: Oxidation-reduction potential; TC: Total carbon; TOC: Total organic carbon; TN: Total nitrogen; $\mathrm{NH}_{4}-\mathrm{N}$ : Ammonium nitrogen; $\mathrm{NO}_{3}-\mathrm{N}$ : Nitrate nitrogen; $\mathrm{NO}_{2}-\mathrm{N}$ : Nitrite nitrogen; TP: Total phosphorus; $\mathrm{PO}_{4}-\mathrm{P}$ : Phosphate phosphorus; SS: Suspended solid; Gr: Chlorophyta; Bl: Cyanophyta; Br: Bacillariophyta 
表 3 相似性分析(ANOSIM)检验 11 个流域间瘤棘奈氏虫种群形态差异 ${ }^{\mathrm{a})}$

Table 3 Analysis of similarity (ANOSIM) statistics testing the difference in morphometric characteristics of N. tuberspinifera population from 11 watersheds, China

\begin{tabular}{|c|c|c|c|c|c|}
\hline \multirow{2}{*}{ 组间 } & \multicolumn{2}{|c|}{ 流域 } & \multirow{2}{*}{ 组间 } & \multicolumn{2}{|c|}{ 流域 } \\
\hline & $R$ & $P$ & & $R$ & $P$ \\
\hline 流域(11流域) & 0.558 & 0.001 & 木兰溪 vs. 晋江 & 0.572 & 0.001 \\
\hline 长江 vs. 钱塘江 & 0.915 & 0.001 & 木兰溪 vs. 东西溪 & 0.445 & 0.001 \\
\hline 长江 vs. 三十六脚湖 & 0.836 & 0.001 & 木兰溪 vs. 珠江 & -0.002 & 0.511 \\
\hline 长江 vs. 木兰溪 & 0.846 & 0.001 & 木兰溪 vs. 南流江 & 0.136 & 0.001 \\
\hline 长江 vs. 晋江 & 0.852 & 0.001 & 木兰溪 vs. 昌化江 & 0.155 & 0.001 \\
\hline 长江 vs. 东西溪 & 0.854 & 0.001 & 木兰溪 vs. 万泉河 & 0.442 & 0.001 \\
\hline 长江 vs. 珠江 & 0.813 & 0.001 & 木兰溪 vs. 太阳河 & 0.349 & 0.001 \\
\hline 长江 vs. 南流江 & 0.851 & 0.001 & 晋江 vs. 东西溪 & 0.067 & 0.066 \\
\hline 长江 vs. 昌化江 & 0.880 & 0.001 & 晋江 vs. 珠江 & -0.090 & 1.000 \\
\hline 长江 vs. 万泉河 & 0.854 & 0.001 & 晋江 vs. 南流江 & -0.031 & 0.843 \\
\hline 长江 vs. 太阳河 & 0.857 & 0.001 & 晋江 vs. 昌化江 & 0.591 & 0.001 \\
\hline 钱塘江 vs. 三十六脚湖 & 0.749 & 0.001 & 晋江 vs. 万泉河 & -0.071 & 0.958 \\
\hline 钱塘江 vs. 木兰溪 & 0.338 & 0.001 & 晋江 vs. 太阳河 & 0.046 & 0.002 \\
\hline 钱塘江 vs. 晋江 & 0.889 & 0.001 & 东西溪 vs. 珠江 & -0.146 & 1.000 \\
\hline 钱塘江 vs. 东西溪 & 0.900 & 0.001 & 东西溪 vs. 南流江 & -0.105 & 0.992 \\
\hline 钱塘江 vs. 珠江 & 0.237 & 0.001 & 东西溪 vs. 昌化江 & 0.507 & 0.001 \\
\hline 钱塘江 vs. 南流江 & 0.537 & 0.001 & 东西溪 vs. 万泉河 & 0.190 & 0.001 \\
\hline 钱塘江 vs. 昌化江 & 0.199 & 0.001 & 东西溪 vs.太阳河 & 0.042 & 0.203 \\
\hline 钱塘江 vs. 万泉河 & 0.901 & 0.001 & 珠江 vs. 南流江 & -0.035 & 1.000 \\
\hline 钱塘江 vs. 太阳河 & 0.734 & 0.001 & 珠江 vs. 昌化江 & 0.056 & 0.059 \\
\hline 三十六脚湖 vs. 木兰溪 & 0.221 & 0.001 & 珠江 vs. 万泉河 & -0.176 & 1.000 \\
\hline 三十六脚湖 vs. 晋江 & 0.103 & 0.082 & 珠江 vs. 太阳河 & -0.110 & 1.000 \\
\hline 三十六脚湖 vs. 东西溪 & 0.289 & 0.001 & 南流江 vs. 昌化江 & 0.295 & 0.001 \\
\hline 三十六脚湖 vs. 珠江 & -0.117 & 0.999 & 南流江 vs. 万泉河 & -0.162 & 1.000 \\
\hline 三十六脚湖 vs. 南流江 & -0.075 & 0.935 & 南流江 vs. 太阳河 & -0.044 & 0.955 \\
\hline 三十六脚湖 vs. 昌化江 & 0.271 & 0.002 & 昌化江 vs. 万泉河 & 0.499 & 0.001 \\
\hline 三十六脚湖 vs. 万泉河 & 0.244 & 0.001 & 昌化江 vs. 太阳河 & 0.444 & 0.001 \\
\hline 三十六脚湖 vs. 太阳河 & 0.066 & 0.189 & 万泉河 vs. 太阳河 & -0.103 & 0.997 \\
\hline
\end{tabular}

a) 比较分析的形态特征参数包括壳高、壳直径、壳口直径、壳刺数、壳刺长

库中瘤棘奈氏虫虫体密度过低，仅进行了一次采样(包 括5个站位)而产生的假阴性. 南溪水库中瘤棘奈氏虫密 度很低则可能存在未知的限制因素, 需要进一步研究.

\section{3 壳口直径是决定瘤棘奈氏虫种群形态差异的主 要特征}

刘乐冕等人 ${ }^{[14]}$ 的研究发现, 瘤棘奈氏虫为单一形 态种，壳高、壳直径、壳口直径可以作为瘤棘奈氏虫 形态分析的主要特征。壳口是瘤棘奈氏虫与外界进行
物质交流的关键场所, 受外界影响相对较大, 其相对变 化幅度十分明显 ${ }^{[14,17]}$. 本研究通过对不同季节和不同 流域间瘤棘奈氏虫种群形态的分析发现，壳口直径差 异是导致瘤棘奈氏虫在时间和空尺度上种群形态差异 的主要因素. 因此, 壳口直径可优先作为瘤棘奈氏虫形 态分化首选指标. Bobrov和Mazei ${ }^{[22]}$ 发现，同一种有壳 虫为适应不同的生境会形成具有一定形态差异的种群. 我们的结果表明, 食物(藻类)和浊度可能影响了瘤棘奈 氏虫种群壳口直径季节差异, 其中食物(尤其是硅藻)对 

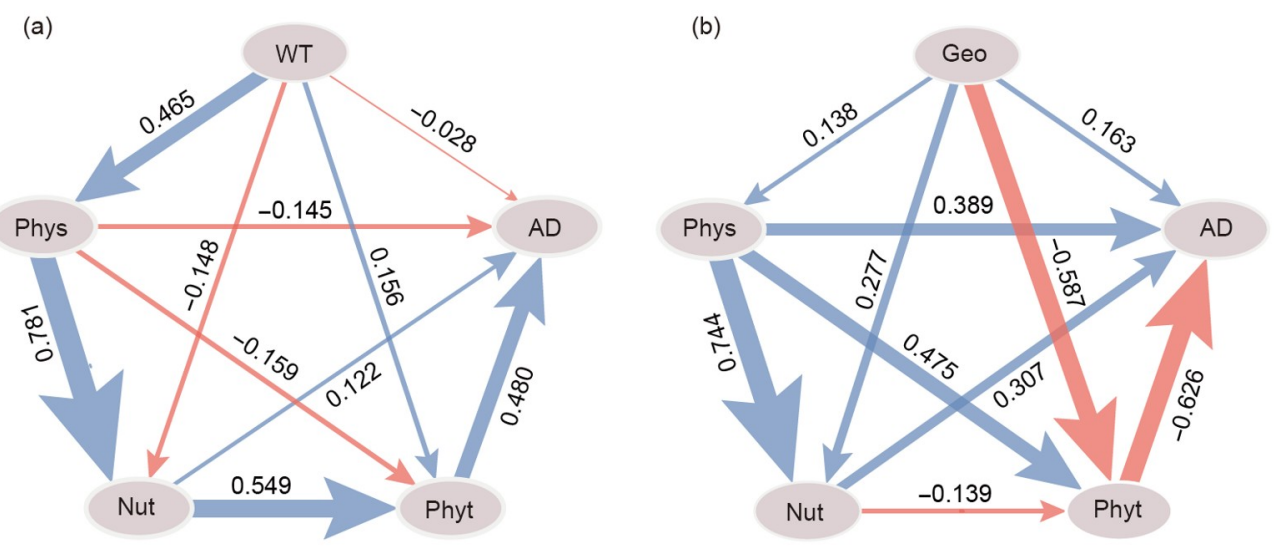

图 7 水温/地理因子、理化因子、营养盐和浮游藻类对瘤棘奈氏虫壳口直径的直接和间接影响. 蓝色和红色线条分别代表正和负的影响. 线 条的粗细代表路径系数. 模型拟合度GOF值在汀溪水库(a)和11个流域24座水库(b)中分别为 0.469 和0.646. (a) 中WT: 水温; Phys: 水深、电导 率、 $\mathrm{pH}$; Nut: 总碳、总有机碳、硝态氮和亚硝态氮; Phyt: 硅藻叶绿素、总叶绿素 $a$; AD: 汀溪水库瘤棘奈氏虫壳口直径. (b) 中Geo: 经度、纬度; Phys: 水深、悬浮颗粒、透明度、浊度; Nut: 总碳、总有机碳、总磷; Phyt: 总叶绿素 $a$; AD: 24座水库中瘤棘奈氏虫壳口直径

Figure 7 The direct and indirect effects of water temperature or geographical factors, physico-chemical factors, nutrients, phytoplankton on the aperture diameter of $N$. tuberspinifera. The blue and red lines represent positive and negative effects, respectively. The thickness of the line represents the value of the path coefficient. Goodness of fit index was 0.469 and 0.646 for Tingxi Reservoir (a) and 11 watersheds (24 reservoirs) (b), respectively. WT: Water temperature; Phys: Water depth, electrical conductivity, $\mathrm{pH}$; Nut: Total carbon, total organic carbon, nitrate nitrogen, nitrite nitrogen; Phyt: Bacillariophyta, total chlorophyll- $a$; AD: The aperture diameter of $N$. tuberspinifera in (a). Geo: Longitude, latitude; Phys: Water depth, suspended solid, transparency, turbidity; Nut: Total carbon, total organic carbon, total phosphorus; Phyt: Total chlorophyll- $a$; AD: The aperture diameter of $N$. tuberspinifera from 24 reservoirs in (b)

壳口直径的独立影响相对更高，这可能与瘤棘奈氏虫 对硅藻的偏好性相关. 瘤棘奈氏虫壳体对硅元素的需 求较高. 杨军等人 ${ }^{[8]}$ 曾报道硅是瘤棘奈氏虫壳体最主 要的元素, 平均含量为 $57.29 \%$. 空间尺度上, 不同流域 间瘤棘奈氏虫种群形态也表现出显著差异, 尤其是长 江流域种群壳口直径显著高于其他流域. 瘤棘奈氏虫 种群壳口直径在空间尺度上的差异受到总碳、食物 (藻类)、浊度和纬度的显著影响, 尤其是总碳、食物与 浊度相对影响较高. 本研究中, 长江流域水体总碳、叶 绿素 $a$ 和浊度均显著高于其他流域, 尤其是长江流域水 体浊度是其他流域的4倍左右(长江流域均值： 14.6 NTU; 其他流域均值: 3.7 NTU). 因此, 我们推测, 相对 丰富的碳含量、食物(藻类)和较高的浊度可能与长江 流域瘤棘奈氏虫壳口直径偏大密切相关. 相对高的浊 度表明, 长江流域水体中颗粒物含量较高, 在食物和颗 粒物含量相对更丰富的水体中, 较大的壳口直径可能 更有利于瘤棘奈氏虫的摄食. 但是, 具体内在生态关系 和机制有待深人研究.

\section{4 结论}

瘤棘奈氏虫种群的地理分布与纬度、海拔和温度
密切相关，在中国主要分布于低纬度、低海拔、高温 度的亚热带和热带地区，特别是在中营养和轻度富营 养水体密度较高. 在时间尺度上, 瘤棘奈氏虫种群密度 在厦门汀溪水库存在显著的季节性变化规律，夏秋季 节密度较高, 水温和食物(藻类)是关键影响因子, 其中 水温的影响更大. 空间尺度上, 瘤棘奈氏虫种群密度受 到地理因素的限制, 随经度、纬度的升高而降低, 同时 食物(藻类)、电导率和硝态氮也对种群密度的空间分 布存在显著影响.

壳口直径的差异是决定瘤棘奈氏虫种群在季节和 流域间形态差异的主要特征; 汀溪水库中夏季瘤棘奈 氏虫种群形态的多元分散指数显著低于其他季节, 食 物(藻类)是影响壳口直径季节差异的主要因子, 尤其是 硅藻. 这可能与瘤棘奈氏虫自身壳体对硅元素的大量 需求相关. 在空间尺度上, 长江流域瘤棘奈氏虫种群壳 口直径明显高于其他流域, 其中长江流域水体相对丰 富的碳含量、藻类和相对高的浊度可能是影响瘤棘奈 氏虫壳口直径的因素. 本研究通过对瘤棘奈氏虫集合 种群在时空尺度上差异的研究, 为未来深人研究瘤棘 奈氏虫种群多样性提供了基础数据，为亚热带和热带 水库生态评价与环境保护提供了科学依据. 


\section{参考文献}

1 Charman D J. Biostratigraphic and palaeoenvironmental applications of testate amoebae. Quat Sci Rev, 2001, 20: 1753-1764

2 Mitchell E A D, Charman D J, Warner B G. Testate amoebae analysis in ecological and paleoecological studies of wetlands: Past, present and future. Biodivers Conserv, 2008, 17: 2115-2137

$3 \mathrm{Ju}$ L, Yang J, Liu L, et al. Diversity and distribution of freshwater testate amoebae (Protozoa) along latitudinal and trophic gradients in China. Microb Ecol, 2014, 68: 657-670

4 Ndayishimiye J C, Ju L, Li H, et al. Temperature transfer functions based on freshwater testate amoebae from China. Eur J Protistol, 2019, 69: 152164

5 Shen Y F. Protozoa of the Tibetan Plateau (in Chinese). In: Jiang X Z, Shen Y F, Gong X J, eds. Aquatic Invertebrates of the Tibetan Plateau. Beijing: Science Press, 1983. 48-100 [沈暳芬. 西藏高原的原生动物. 见: 蒋隻治, 沈韦昷芬, 龚循矩, 编. 西藏水生无脊椎动物. 北京: 科学出版 社, 1983. 48-100]

6 Meisterfeld R. Order Arcellinida Kent, 1880. In: Lee J J, Leedale G F, Bradbury P, eds. The Illustrated Guide to the Protozoa. 2nd ed. Lawrence Kansas: Allen Press, 2002. 827-860

7 Yang J, Beyens L, Shen Y F, et al. Redescription of Difflugia tuberspinifera Hu, Shen, Gu et Gong, 1997 (Protozoa: Rhizopoda: Arcellinida: Difflugiidae) from China. Acta Protozool, 2004, 43: 281-289

8 Yang J, Beyens L, Shen Y F, et al. Elemental composition of the shell of the testate amoeba Difflugia tuberspinifera (Sarcodina: Rhizopoda) (in Chinese). Zool Res, 2004, 25: 452-455 [杨军, Beyens L, 沈暳芬, 等. 瘤棘砂壳虫(肉足亚门: 根足总纲)壳体元素组成. 动物学研究, 2004, 25 452-455]

9 Yang J, Feng W S, Shen Y F. On new records of the genus Difflugia from China (Sarcomastigophora, Rhizopoda, Lobosea, Arcellinida, Difflugiidae) (in Chinese). Acta Zootax Sin, 2004, 29: 239-247 [杨军, 冯伟松, 沈暳芬. 中国砂壳虫属新纪录(肉鞭门, 根足总纲, 叶足纲, 表科 目, 砂壳科). 动物分类学报, 2004, 29: 239-247]

10 Yang J, Zhang W, Feng W, et al. Geographical distribution of testate amoebae in Tibet and northwestern Yunnan and their relationships with climate. Hydrobiologia, 2006, 559: 297-304

11 Albert J S, Destouni G, Duke-Sylvester S M, et al. Scientists' warning to humanity on the freshwater biodiversity crisis. Ambio, 2021, 50: 85-94

12 Gomaa F, Yang J, Mitchell E A D, et al. Morphological and molecular diversification of Asian endemic Difflugia tuberspinifera (Amoebozoa, Arcellinida): A case of fast morphological evolution in protists? Protist, 2015, 166: 122-130

13 Gomaa F, Lahr D J G, Todorov M, et al. A contribution to the phylogeny of agglutinating Arcellinida (Amoebozoa) based on SSU rRNA gene sequences. Eur J Protistol, 2017, 59: 99-107

14 Liu L M, Yang J, Zhang W J, et al. Morphometric analysis of six natural populations of Difflugia tuberspinifera (in Chinese). Zool Res, 2010, 31: 435-443 [刘乐冕, 杨军, 张文静, 等. 原生动物瘤棘砂壳虫六个自然种群的形态计量学分析. 动物学研究, 2010, 31: 435-443]

15 Han B P, Wang T, Lin Q Q, et al. Carnivory and active hunting by the planktonic testate amoeba Difflugia tuberspinifera. Hydrobiologia, 2008, 596: 197-201

16 Han B P, Wang T, Xu L, et al. Dynamics in space and time of four testate amoebae (Difflugia spp.) co-existing in the zooplankton of a reservoir in southern China. Eur J Protistol, 2011, 47: 224-230

17 Yu Z, Zhang W, Liu L, et al. Evidence for two different morphotypes of Difflugia tuberspinifera from China. Eur J Protistol, 2014, 50: 205211

$18 \mathrm{Hu} \mathrm{D} \mathrm{L}$, Shen Y F, Gu M R, et al. New species and new records of protozoa from Wuling Mountains Area (in Chinese). In: Song D X, ed. Invertebrates of Wuling Mountains Area, Southwestern China. Beijing: Science Press, 1997. 40-72 [胡东利, 沈暳芬, 顾曼如, 等. 武陵山地区原 生动物新种和新纪录. 见: 宋大祥, 编. 西南武陵山地区无脊椎动物. 北京: 科学出版社, 1997. 40-72]

19 Anderson O R. Some observations of feeding behavior, growth, and test particle morphology of a silica-secreting testate amoeba Netzelia tuberculata (Wallich) (Rhizopoda, Testacea) grown in laboratory culture. Arch Protistenkd, 1989, 137: 211-221

20 Ogden C G, Meisterfeld R. The taxonomy and systematics of some species of Cucurbitella, Difflugia and Netzelia (Protozoa: Rhizopoda); with an evaluation of diagnostic characters. Eur J Protistol, 1989, 25: 109-128

21 Wang L N, Yu Z, Tian Y, et al. Diet composition of Difflugia tuberspinifera (testate amoeba) based on a clone library technique (in Chinese). Acta Ecol Sin, 2015, 35: 6183-6188 [王丽娜, 余正, 田野, 等. 基于克隆文库技术分析瘤棘砂壳虫的食物组成. 生态学报, 2015, 35: 6183-6188]

22 Bobrov A, Mazei Y. Morphological variability of testate amoebae (Rhizopoda: Testacealobosea and Testaceafilosea) in natural populations. Acta Protozool, 2004, 43: 133-146

23 Wanner M. A review on the variability of testate amoebae: Methodological approaches, environmental influences and taxonomical implications. Acta Protozool, 1999, 38: 15-29 
24 Yang J, Zhang W, Shen Y. Relationships between testate amoebae assemblages (Protozoa) and geographic factors in Yunnan Plateau lakes, China. J Freshw Ecol, 2009, 24: 437-443

25 Yang J, Yu X, Liu L, et al. Algae community and trophic state of subtropical reservoirs in southeast Fujian, China. Environ Sci Pollut Res, 2012, 19: $1432-1442$

26 Cole G A. Textbook of Limnology. Long Grove: Waveland Press, 1994

27 Greenberg A E, Clesceri L S, Eaton A D. Standard Methods for the Examination of Water and Wastewater. Washington DC: American Public Health Association, 1992

28 Liu L, Zhang D, Lü H, et al. Plankton communities along a subtropical urban river (Houxi River, southeast China) as revealed by morphological and molecular methods. J Freshw Ecol, 2013, 28: 99-112

29 R Core Team. R: A Language and Environment for Statistical Computing. R Foundation for Statistical Computing, Vienna, Austria, 2020

30 Gao X, Chen H, Govaert L, et al. Responses of zooplankton body size and community trophic structure to temperature change in a subtropical reservoir. Ecol Evol, 2019, 9: 12544-12555

31 Olea P P, Mateo-Tomás P, de Frutos A. Estimating and modelling bias of the hierarchical partitioning public-domain software: Implications in environmental management and conservation. PLoS One, 2010, 5: e11698

32 Wang W, Ren K, Chen H, et al. Seven-year dynamics of testate amoeba communities driven more by stochastic than deterministic processes in two subtropical reservoirs. Water Res, 2020, 185: 116232

33 Sanchez G. PLS Path Modeling with R (Trowchez Editions). 2013

34 Gao X, Chen H, Gu B, et al. Particulate organic matter as causative factor to eutrophication of subtropical deep freshwater: Role of typhoon (tropical cyclone) in the nutrient cycling. Water Res, 2021, 188: 116470

$35 \mathrm{Lu}$ X T, Gao Y Y, Weisse T. Functional ecology of two contrasting freshwater ciliated protists in relation to temperature. J Eukaryot Microbiol, 2021, 68: e12823

36 Zhang Z S, Huang X F. Research Methods of Freshwater Plankton (in Chinese). Beijing: Science Press, 1991 [章宗涉, 黄祥飞. 淡水浮游生物研 究方法. 北京: 科学出版社, 1991]

37 Yang Y F, Huang X F. The influence of silver carp and bighead on the zooplankton community structure (in Chinese). J Lake Sci, 1992, 4: 78-86 [杨宇峰, 黄祥飞. 鲢鳙对浮游动物群落结构的影响. 湖泊科学, 4: 78-86]

38 Gao Y, Zhou F, Ciais P, et al. Human activities aggravate nitrogen-deposition pollution to inland water over China. Natl Sci Rev, 2020, 7: 430440

39 Huang J C, Zhang Y J, Arhonditsis G B, et al. How successful are the restoration efforts of China's lakes and reservoirs? Environ Int, 2019, 123: $96-103$

40 Yang Y, Chen H, Abdullah Al M, et al. Urbanization reduces resource use efficiency of phytoplankton community by altering the environment and decreasing biodiversity. J Environ Sci, 2022, 112: 140-151

41 Peng F, Guo Y, Isabwe A, et al. Urbanization drives riverine bacterial antibiotic resistome more than taxonomic community at watershed scale. Environ Int, 2020, 137: 105524

42 Sun J, He F, Zhang Y, et al. Investigation and analysis of fish in restoration area of submerged plants in the lake district of West Lake, Hangzhou (in Chinese). Chin J Fish, 2021, 34: 72-77 [孙健, 贺锋, 张义, 等. 杭州西湖子湖湖区沉水植物群落恢复区鱼类调查与分析. 水产学杂志, 2021, 34 72-77]

43 Wang H L, Diao J R, Qian W J, et al. The spatial and temporal distribution of heterotrophic bacteria in Dongqian Lake and it's relationship with the environmental factors and the organic matter (in Chinese). Ecol Sci, 2020, 39: 85-92 [王海丽, 刀俊睿, 钱文杰, 等. 东钱湖水体异养细菌的时空 分布及其与环境影响因素和有机质的关系. 生态科学, 2020, 39: 85-92]

44 Xiong J, Jiang X M, Wang C M, et al. Community variation of macrozoobenthos and bioassessment of Dongqian Lake, Ningbo (in Chinese). Res Environ Sci, 2012, 25: 282-289 [熊晶, 蒋小明, 王丑明, 等. 宁波东钱湖大型底栖动物群落动态及水质生物学评价. 环境科学研究, 2012, 25: 282-289]

\section{补充材料}

表S1 中国88个湖库中瘤棘奈氏虫分布信息

本文以上补充材料见网络版csb.scichina.com. 补充材料为作者提供的原始数据, 作者对其学术质量和内容负责. 


\title{
Spatial-temporal variation of Netzelia tuberspinifera population density and morphometric characteristics in China and its driving factors
}

\author{
Wenping Wang ${ }^{1,2}$, Xiaofei Gao ${ }^{1,3}$, Huihuang Chen ${ }^{1,2}$, Kexin Ren ${ }^{1}$, Lei Jin ${ }^{1,2}$ \& Jun Yang ${ }^{1 *}$ \\ ${ }^{1}$ Aquatic EcoHealth Group, Fujian Key Laboratory of Watershed Ecology, Key Laboratory of Urban Environment and Health, Institute of Urban \\ Environment, Chinese Academy of Sciences, Xiamen 361021, China; \\ ${ }^{2}$ University of Chinese Academy of Sciences, Beijing 100049, China; \\ ${ }^{3}$ College of Fisheries, Henan Normal University, Xinxiang 453007, China \\ * Corresponding author, E-mail: jyang@iue.ac.cn
}

Testate amoebae are a diverse polyphyletic group of single-celled amoeboid protists in which the cytoplasm is enclosed within an external shell. They are widely distributed in various habitats including freshwater, brackish water, soil and moss. They play an important role in the biogeochemical cycles and energy flow of both aquatic and terrestrial ecosystems. They can provide a good record or proxy of past environmental change due to their environmental sensitivity and high diversity. Recent research on these microorganisms suggests they have been increasingly used as a biotic proxy of environmental and climatic reconstruction, water quality and pollution. Many testate amoeba species have a cosmopolitan distribution at least at the morphological level, but others have restricted geographical distribution. In China, we found there are abundant and diverse testate amoebae in reservoirs and lakes, including some endemic species. In recent years, however, the local species diversity of testate amoebae has been decreasing due to rapid increases in the level of reservoir or lake eutrophication. Currently, the conservation and sustainable use of biodiversity has become an important topic, so it is necessary and urgent to conduct systematic ecology research for endemic testate amoeba population in China. Netzelia tuberspinifera (basionym Difflugia tuberspinifera) is an endemic sensitive species of East Asia and is widely distributed in southern China. We found that the distribution of $N$. tuberspinifera was significantly related to latitude, elevation and temperature based on the datasets of 88 lakes and reservoirs in China, and this microorganism was mainly distributed in subtropical and tropical lakes and reservoirs characterized by low latitude, low elevation and high water temperature. Our study investigated the spatial-temporal distribution of $N$. tuberspinifera based on a high-frequency time series, sampled over four years from Tingxi Reservoir (Xiamen, China) combined with spatial samples from 28 reservoirs in 14 watersheds in southern China, and to reveal the ecological factors and processes that shape its distributions. The results showed that water temperature and foods (phytoplankton) exhibited significant effects on seasonal patterns of $N$. tuberspinifera population density $(0-10.7$ ind/L), with a higher correlation coefficient for water temperature than for food. In the Tingxi Reservoir, surface water temperature ranged from 14.3 to $32.1^{\circ} \mathrm{C}$ over four years from 2016 to 2019 . When water temperature was above $30^{\circ} \mathrm{C}, N$. tuberspinifera displayed better growth and reproduction, so its population density was higher in summer and autumn than in other seasons. On the spatial scale, the population density of $N$. tuberspinifera was $0-19.2 \mathrm{ind} / \mathrm{L}$, which was mainly limited by geographical factors and decreased with an increase in latitude and longitude, respectively. Meanwhile, foods (phytoplankton), electrical conductivity and nitrate nitrogen also had significant effects on $N$. tuberspinifera population density. Interestingly, the variation in aperture diameter $(33.5-68.2 \mu \mathrm{m}$ in Tingxi Reservoir; 33.5-73.6 $\mu \mathrm{m}$ in 11 watersheds) of $N$. tuberspinifera was the major contributing factor in explaining the temporal-spatial differences of population morphological characteristics. Furthermore, we found that foods (phytoplankton) play a key role in the difference of aperture diameter between different seasons in Tingxi Reservoir. The difference in aperture diameter between the Yangtze River and other watersheds was mainly affected by foods (phytoplankton), total carbon and water turbidity. Based on the spatial-temporal difference of the $N$. tuberspinifera metapopulation, our work improves the understanding of geographical distribution and diversity of testate amoebae, and provides important references for ecological evaluation and biodiversity conservation in subtropical and tropical reservoirs.

testate amoebae, Netzelia tuberspinifera, geographical distribution, temporal variation, population density, morphometric characteristics

doi: 10.1360/TB-2021-0587 